\title{
COMPROMETIMENTO ORGANIZACIONAL EM ORGANIZAÇÕES AUTENTIZÓTICAS: UM ESTUDO LUSO-BRASILEIRO
}

RESUMO

Este artigo tem o objetivo de mostrar como as percepções dos indivíduos acerca de seis características organizacionais autentizóticas - espírito de camaradagem, credibilidade do superior, comunicação aberta com o superior, oportunidades de aprendizagem e desenvolvimento pessoal, eqüidade e conciliação trabalho-família - explicam três dimensões do comprometimento organizacional. Na primeira fase, replicou-se estudo anterior, realizado em Portugal, com o objetivo de operacionalizar o construto das organizações autentizóticas. Na segunda fase, realizaram-se estudos confirmatórios, em Portugal e no Brasil. A evidência empírica salienta as boas propriedades psicométricas do construto e mostra como as variáveis autentizóticas explicam o comprometimento, sobretudo o componente afetivo. As dimensões autentizóticas mais relevantes são o espírito de camaradagem, a credibilidade do superior e as oportunidades de aprendizagem e desenvolvimento pessoal.

\section{Arménio Rego \\ Universidade de Aveiro \\ Solange Souto \\ Faculdades Ibmec e UERJ}

\begin{abstract}
The paper aims to show how the perceptions of six authentizotic organizational characteristics - spirit of camaraderie, credibility of the leader, open and frank communication with the leader, opportunities for learning and self-development, equity, work-family conciliation explain three dimensions of organizational commitment. In the first step, a study carried in Portugal to build and validate the authentizotic organizations construct was replicated in Brazil. In the second step, confirmatory studies were carried out in Portugal and Brazil. Empirical evidence suggests the good psychometric properties of the construct and shows that authentizotic dimensions explain commitment, mainly the affective component. The authentizotic dimensions suggesting the higher predictive power are the spirit of camaraderie, the credibility of the leader and the opportunities for learning and self-development.
\end{abstract}

PALAVRAS-CHAVE Organizações autentizóticas, clima organizacional, comprometimento organizacional, saúde individual, saúde organizacional.

KEY WORDS Authentizotic organizations, organizational climate, organizational commitment, organizational health, individual health. 


\section{INTRODUÇÃo}

A "insalubridade psicológica" de muitas organizações tem sido citada com profusão na literatura, como, por exemplo, nos trabalhos de Bowles (1997), Ganster e Murphy (2000), Hart e Cooper (2001), e Kets de Vries (2001). Kets de Vries (2001) respondeu a essas inquietações propondo o conceito de organizações autentizóticas. O termo é um neologismo resultante de duas palavras gregas: authenteekos e zoteekos. A primeira significa que a organização é autêntica, merecedora de confiança. A segunda significa que ela é vital para as pessoas, fornecendo significado para as suas vidas. As organizações autentizóticas são, portanto, aquelas que ajudam os colaboradores a estabelecer um equilíbrio entre a vida pessoal e a organizacional. Elas são um antídoto para o estresse vigente em muitas organizações modernas e proporcionam às pessoas a oportunidade de atenderem os sete sentidos que compõem a existência humana e profissional: de propósito, de autodeterminação, de impacto, de competência, de pertencimento, de prazer e alegria, e de significado.

Este artigo enfoca o modo como se operacionalizou o construto e mostra, empiricamente, como as percepções de seis características organizacionais autentizóticas explicam o comprometimento organizacional. $\mathrm{O}$ quadro teórico utilizado é o dos climas psicológicos (Jones e James, 1979; Glick, 1985; Burke, Borucki e Kaufman, 2002). O estudo aborda o nível de análise individual, sendo o nível organizacional desconsiderado. Dessa forma, considera as percepções dos indivíduos acerca do ambiente de trabalho, mas não as agrega para a obtenção de avaliações organizacionais. Portanto, testa o grau em que essas percepções explicam o comprometimento organizacional.

O texto começa por se referir à "insalubridade psicológica" de muitas organizações e sugere que as organizações autentizóticas são uma resposta possível a essa questão. Em seguida, apresentam-se diversos conceitos próximos do conceito de organização autentizótica, evidencia-se o modo como Rego (2003) operacionalizou de forma exploratória o construto e explica-se o conceito e as dimensões do comprometimento organizacional, enfatizando-se as hipóteses acerca do grau em que elas podem ser explicadas pelas variáveis autentizóticas. Em seguida, apresentam-se a metodologia usada no estudo empírico e os principais resultados. Na seção final, identificam-se as limitações da pesquisa e sugerem-se possíveis caminhos de investigação futura.

\section{REFERENCIAL TEÓRICO}

\section{"Insalubridade psicológica" das organizações}

O valor do conceito de organizações autentizóticas surge de forma emblemática de uma constatação expressa por Kets de Vries (2001, p. 101):

\begin{abstract}
As estatísticas acerca das doenças, do fraco desempenho e do absenteísmo relatam uma história dramática acerca das disfunções geradas pelo trabalho. Em muitas organizações, foi completamente perdido o equilíbrio entre as vidas pessoal e do trabalho. Histórias horrorosas sobre liderança disfuncional, sobrecarga de trabalho, exigências de trabalho conflitantes, comunicação empobrecida, ausência de oportunidades para progressão na carreira, iniqüidades nas avaliações de desempenho e nas remunerações, restrições ao comportamento e excessivas viagens conduzem a reações depressivas, alcoolismo, abuso de drogas e perturbações do sono.
\end{abstract}

Esse pessimismo, parcialmente resultante da constatação dos efeitos perversos de alguns processos de downsizing e de reengenharia, coabita com inúmeras referências à desumanização do trabalho. Por exemplo, Bowles (1997) destacou as lógicas competitivas que impregnam muitas organizações, sugerindo que o mito da gestão que enfatiza a ética competitiva é antagônico do progresso humano. A dimensão humana é esquecida e os indivíduos passam a desempenhar o papel de meros instrumentos. Como afirma Bowles (1997, p. 800), "o efeito líquido é uma crescente patologia social e individual". Em vertente similar, Kanungo e Mendonça (1996, p. 4) afirmaram que:

Muitos empregados, afortunados por terem emprego, também verificam que o trabalho não só não lhes proporciona uma oportunidade para desenvolvimento e auto-realização, como também são uma fonte de ansiedade e insegurança, devido à apreensão de que possam ser os próximos a serem sacrificados no altar dos objetivos de curto prazo.

Rego (2002a, p. 16) fez alusão ao paradoxo do mundo organizacional atual, afirmando que a reivindicação da "entrega" dos indivíduos à organização coabita com um certo "descarte" da própria organização perante eles. Scott (1992) notou intuitos de manipulação em algumas teorias da gestão, mostrando que lhes subjaz a idéia de que se pode obter mais produtividade de 
trabalhadores satisfeitos como se pode extrair mais leite de vacas contentes.

A própria literatura sobre estresse (e.g. Cooper, Dewe e O'Driscoll, 2001; Ganster e Murphy, 2000; Hart e Cooper, 2001) é rica em referências à presença marcante de fatores de estresse na vida organizacional e aos efeitos perversos daí oriundos, tanto para os indivíduos (fadiga, problemas cardiovasculares e gastrintestinais, depressão e conflitos familiares), como para as organizações (absenteísmo, quebras do desempenho e erros decisórios). O Guia do estresse ocupacional da Comissão Européia (European Commission, 1999) ilustra essa situação ao mostrar dados estatísticos cujo teor é inquietante. Alguns desses dados revelam que mais de metade dos trabalhadores da União Européia afirma trabalhar em um ritmo muito elevado e com prazos muito reduzidos; mais de um terço não exerce nenhuma influência na seqüência das tarefas que lhes são confiadas; mais de $25 \%$ não têm influência sobre seu ritmo de trabalho; $45 \%$ afirmam executar tarefas monótonas; $44 \%$ não possuem rotatividade de funções; e 55\% executam tarefas curtas e repetitivas. O documento diz que uma estimativa moderada dos custos causados pelo estresse no trabalho chega a 20 bilhões de euros anuais.

\section{Organizações autentizóticas: conceitos afins}

A proposição do conceito de organização autentizótica é uma tentativa de resposta a todas essas preocupações. O conceito compartilha diversos traços com as "empresas vivas" (De Geus, 1997a), as "empresas amigas da família" (Den Dulk, Van Doorne-Huiskes e Schippers, 1999; Thompson, Beauvais e Lyness, 1999), a "empresa humanizada" (Vergara e Branco, 2001) e o "sentido psicológico de comunidade de trabalho" (Burroughs e Eby, 1998). A sua gênese baseia-se no projeto The 100 Best Companies to Work for in America (Levering e Moskowitz, 1983, 1998, 2003).

Um "bom local de trabalho" é aquele em que os empregados confiam nas pessoas para as quais trabalham, têm orgulho do que fazem e sentem prazer em trabalhar com os outros. As culturas dessas empresas estão permeadas por valores que acabam por se traduzir em formas específicas de comportamento que, segundo Kets de Vries (2001, p. 107), são a confiança, a alegria, a franqueza, o respeito pelo indivíduo, a justiça, o trabalho de equipe, o empreendorismo e a inovação, a orientação para o cliente, a responsabilidade, a aprendizagem contínua e a abertura para a mudança. Essas empresas oferecem diversos tipos de benefícios, tais como formação e treinamento, conciliação trabalho-família, participação nos lucros, licenças sabáticas, seguros-saúde, apoio médico, áreas para a prática desportiva, creches e apoio jurídico. Horários flexíveis de trabalho, empregos em tempo parcial e compartilhamento de postos de trabalho são também comuns. E, formal ou informalmente, muitas adotam políticas que evitam demissões.

As empresas "amigas da família" (Den Dulk et al., 1999) são as que demonstram preocupações com as relações familiares de seus colaboradores. Elas oferecem horários flexíveis, salas de amamentação, creches, bons programas para crianças e idosos, licenças-paternidade, serviços de guarda após o horário escolar, esquemas de interrupção de carreira e licença por adoção. Procuram conciliar três dimensões: realização profissional, realização familiar e pessoal, e desempenho organizacional.

As "empresas vivas" (De Geus, 1997a, 1997b) são as que atuam como comunidades humanas, agem responsavelmente perante o meio ambiente e adotam visões de longo prazo, muito além dos interesses econômicos imediatos. Constituem espaços para que os indivíduos tomem iniciativa e sejam escutados. Elas encorajam a experimentação, toleram e promovem idéias novas. Além de entidades econômicas, são também comunidades humanas duradouras. Vêem os seus empregados como membros valiosos, e percebem que o lucro é apenas o meio de concretizar o objetivo real da organização: aumentar a sua esperança de vida.

A "empresa humanizada" é uma expressão usada por Vergara e Branco (2001, p. 22) para designar as organizações que, segundo os autores, além de focalizarem a preservação ambiental:

[...] promovem a melhoria da qualidade de vida e de trabalho, visam à construção de relações mais democráticas e justas, mitigam as desigualdades e diferenças de raça, sexo ou credo, além de contribuírem para o desenvolvimento das pessoas sob os aspectos físico, emocional, intelectual e espiritual.

Os autores defendem a tese de que essas empresas representam uma via de operacionalização da emergência de um novo paradigma, centrado na ética, na responsabilidade social, na cidadania corporativa e no desenvolvimento sustentável. Acrescentam que elas são necessárias para romper com um modelo empresarial e econômico apenas focalizado nos resultados econômicos e financeiros. Argumentam ainda que elas são 
uma resposta à "inadiável necessidade de conciliação entre competitividade e humanização" (Vergara e Branco, 2001, p. 22).

O construto do "sentido psicológico de comunidade de trabalho" foi operacionalizado por Burroughs e Eby (1998), que identificaram nove dimensões: segurança emocional, apoio dos colegas, orientação para a equipe, vínculo espiritual, sentido de pertença, tolerância para com as diferenças individuais, boa vizinhança, sentido de coletivismo e reflexão. O construto ancora-se na idéia de que o bem-estar psicológico dos indivíduos depende da satisfação de necessidades sociais, de significado, de identidade, de apoio e de pertencimento. Os colaboradores que experimentam o sentido psicológico de comunidade de trabalho reconhecem que a organização vai ao encontro das suas necessidades e das necessidades de suas famílias, e que lhes proporciona uma qualidade de vida superior. Em troca, demonstram comprometimento, lealdade e praticam atos de cidadania organizacional mais freqüentes (Rego, 2002b).

\section{Organizações autentizóticas: operacionalização exploratória do construto}

Com o objetivo de tentar operacionalizar o construto de organização autentizótica, Rego (2003) formulou 57 itens descritores com base na literatura referente às próprias "organizações autentizóticas", às empresas "amigas da família", às "empresas vivas", às "melhores empresas para trabalhar" e ao "sentido psicológico de comunidade de trabalho". Em seguida, elaborou um questionário, aplicado a uma amostra de 183 colaboradores de 162 organizações portuguesas. A análise das componentes principais sugeriu a remoção de 31 itens. Dos 26 remanescentes, emergiu uma estrutura com seis dimensões:

- Espírito de camaradagem. Compreende itens que refletem: (a) o sentido de pertencimento contemplado nas "organizações autentizóticas"; (b) o espírito de camaradagem e o orgulho, presentes nas "melhores empresas para se trabalhar"; e (c) o apoio dos colegas, a orientação para a equipe, o sentido de pertencimento, o sentido de vizinhança e o sentido de coletivismo, presentes no "sentido psicológico de comunidade de trabalho".

- Comportamento respeitador de parte dos superiores. Compreende itens que refletem: (a) o respeito, a justiça e a credibilidade presentes nas "melhores empresas para se trabalhar"; e (b) alguns traços do sentido de autodeterminação presente nas "organizações autenti- zóticas".

- Oportunidades de aprendizagem e desenvolvimento pessoal. Compreende itens que refletem: (a) o sentido de competência, o sentido de significado e o sentido de impacto contemplados nas "organizações autentizóticas"; e (b) o respeito presente nas "melhores empresas para se trabalhar".

- Eqüidade. Compreende itens que refletem parcialmente: (a) os sentidos de pertencimento e de propósito impregnados nas "organizações autentizóticas"; e (b) o respeito e a justiça presentes nas "melhores empresas para se trabalhar".

- Conciliação entre as vidas pessoal e profissional. Compreende itens que refletem o respeito característico das "melhores empresas para se trabalhar", assim como o cerne conceitual das "empresas amigas da família".

- Sentido de autodeterminação. Compreende itens que refletem o sentido homônimo das "organizações autentizóticas".

Neste artigo, serão mostrados os resultados da replicação desta investigação, que foi realizada no Brasil. Tal continuidade abriu caminho a estudos confirmatórios realizados com uma amostra portuguesa e outra brasileira, por meio das quais foi possível testar a dimensionalidade do construto e o grau em que as variáveis autentizóticas explicam os comprometimentos afetivo, normativo e instrumental.

\section{Comprometimento organizacional}

O comprometimento organizacional pode ser definido como o laço psicológico que caracteriza a ligação do indivíduo à organização e que reduz a probabilidade de ele a abandonar (Allen e Meyer, 2000). O interesse no conceito baseia-se na evidência de que dele derivam diversas atitudes e comportamentos relevantes, como assiduidade, intenção de abandonar a organização, abandono efetivo, pontualidade, atitudes em face da mudança, desempenho individual, comportamentos de cidadania, comportamentos de negligência e desempenho organizacional (Allen e Meyer, 1996, 2000; Meyer, 1997; Meyer e Herscovitch, 2001; Rego e Souto, 2002). Assim, não surpreende o grande número de pesquisas que visam conhecer as razões pelas quais as pessoas desenvolvem tal laço psicológico.

Todavia, a interpretação de suas conseqüências e de seus antecedentes só pode ser efetiva após a compreensão da sua multidimensionalidade. Embora vários modelos sejam identificáveis, o mais generalizado (Allen e Meyer, 1990, 2000; Meyer e Allen, 1991; 
Meyer, 1997) abrange três componentes: o afetivo (grau em que o colaborador se sente emocionalmente ligado, identificado e envolvido na organização), o normativo (grau em que o colaborador possui um sentido da obrigação, ou dever moral, de permanecer na organização) e o instrumental (grau em que o colaborador se mantém ligado à organização devido ao reconhecimento dos custos associados com a sua saída da empresa).

Alguns autores têm questionado essa tridimensionalidade (e.g. Allen e Meyer, 2000; Meyer e Herscovitch, 2001). Há certo desacordo sobre se o comprometimento afetivo e normativo devem ser tomados como componentes diferentes. Existem também divergências em torno da questão de saber se o comprometimento instrumental deve ser considerado um construto unidimensional ou dividido em duas dimensões - a primeira, a percepção de sacrifícios causados pela saída da organização; e a segunda, a percepção de ausência de alternativas atrativas de emprego fora da atual organização. Apesar dessa dissonância, há tendência a apoiar genericamente o modelo tridimensional (Allen e Meyer, 1990, 1996, 2000; Meyer e Herscovitch, 2001), inclusive no contexto luso-brasileiro (Medeiros e Enders, 1998; Rocha e Bastos, 2000; Rego e Souto, 2002)

Um dos traços mais marcantes desse modelo é a geração de diferentes conseqüências comportamentais (Allen e Meyer, 1996, 2000; Meyer e Herscovitch, 2001). Dado que o comprometimento afetivo resulta da ligação emocional à organização, é provável que os indivíduos afetivamente comprometidos estejam motivados a contribuir mais vigorosamente para a organização, com um menor turnover, absenteísmo mais baixo, desempenho mais elevado e comportamentos superiores de cidadania organizacional. Adicionalmente, o modelo sugere que as pessoas instrumentalmente comprometidas não terão nenhuma tendência para desempenhos que ultrapassem o mínimo esperado. Aliás, se esse for o laço predominante, podem daí resultar comportamentos de trabalho pouco desejáveis. Finalmente, o modelo prediz que os indivíduos normativamente associados à organização tendem a contribuir positivamente para ela. Todavia, os sentimentos de obrigação não suscitam os mesmos entusiasmo e o envolvimento que resultam do laço afetivo.

Sendo distintas as conseqüências de cada componente, é relevante saber se os antecedentes também divergem. A evidência teórica e empírica sugere que, de fato, cada componente tende a desenvolver-se de modo relativamente independente, na base de diferentes antecedentes e por via de diferentes processos (Allen e Meyer, 1996, 2000; Meyer, 1997; Meyer e Herscovitch, 2001). O comprometimento afetivo desenvolve-se quando o indivíduo se sente envolvido com a organização, reconhece valor na relação com ela ou se sente identificado com ela. Por exemplo, alguma evidência sugere que as pessoas reagem com comprometimento afetivo superior quando sentem que a organização e os líderes os tratam de modo justo, respeitador e apoiador (Rego e Souto, 2002). O comprometimento normativo emerge quando o indivíduo interioriza as normas organizacionais por meio da socialização, ou quando recebe benefícios e experiências que o induzem a sentir vontade de agir reciprocamente. $\mathrm{O}$ comprometimento instrumental desenvolve-se quando o indivíduo reconhece perdas em consequência de um eventual abandono da organização ou sente que não tem alternativas atrativas fora dela.

Numa tentativa de síntese, baseada em múltiplas contribuições, pode afirmar-se que: (1) entre os antecedentes que melhor explicam o comprometimento normativo e, sobretudo o afetivo, encontram-se a liderança transformacional, o apoio organizacional, o apoio do supervisor e dos colegas, a recepção de feedback relativo ao desempenho, as funções desafiantes, a percepção de que os valores organizacionais têm orientação humanista e visionária, a percepção de que as organizações são socialmente responsáveis e a percepção de justiça; e (2) a maior parte desses antecedentes correlacionase de forma nula ou negativa com o comprometimento instrumental (Meyer e Allen, 1991; McFarlin e Sweeney, 1992; Sweeney e McFarlin, 1993; Moorman, Niehoff e Organ, 1993; Shore e Wayne, 1993; Allen e Meyer, 1996; Podsakoff, MacKenzie e Bommer, 1996; Bolon, 1997; Medeiros e Enders, 1998; MacKenzie, Podsakoff e Ahearne, 1998; Iverson e Buttigieg, 1999; Maignan, Ferrell e Hult, 1999; Finegan, 2000; Grunberg, Anderson-Connolly e Greenberg, 2000; Rego e Souto, 2002).

Com isso, pode-se propor que as características organizacionais autentizóticas expliquem sobretudo os comprometimentos afetivo e normativo. Na verdade, um exame atento dessas características permite notar várias consonâncias com os antecedentes mencionados. Por exemplo, o espírito de camaradagem revela algumas similaridades com o apoio da organização e dos pares. O comportamento de liderança respeitador evidencia alguma sobreposição com a liderança transformacional, 
a justiça interacional e o apoio dos superiores. A equidade partilha semelhanças com a justiça, especialmente a interacional e a procedimental (Rego e Souto, 2002). As oportunidades de desenvolvimento e aprendizagem revelam alguma sobreposição com os desafios impregnados nas funções. A conciliação trabalho-família apresenta aspectos que mostram ao indivíduo o grau em que a organização o apóia. Em suma, parece haver razões para presumir que as características autentizóticas podem induzir, nos indivíduos, sentimentos de envolvimento e identificação com a organização, assim como o desejo de atuar reciprocamente.

\section{MÉTODO}

A primeira etapa do estudo foi desenvolvida por meio da replicação de um estudo anteriormente realizado em Portugal por Rego (2003). Para a presente pesquisa, a amostra foi composta por 183 membros de sete organizações operando no Brasil, dos quais 57\% trabalhavam em empresas públicas, $41 \%$ eram do sexo masculino, sua idade média era de 35,5 e o seu tempo médio de trabalho era de 6,8 anos. Os indivíduos foram convidados a assinalar o grau de veracidade das 57 afirmações, mediante uma escala de seis pontos (1: "é completamente falsa" ... 6: "é completamente verdadeira").

Solicitou-se que mencionassem a sua intenção de abandono da organização, tendo-lhes sido proposto que assinalassem, mediante a mesma escala de seis pontos, a veracidade de três afirmações colhidas em Robinson (1996) e em Randall et al. (1999). Os dados referentes aos climas autentizóticos foram submetidos a uma análise dos componentes principais, com rotação varimax. Com um processo depurativo que visava uma estrutura dimensional clara, removeram-se os mesmos 31 itens que Rego (2003) havia eliminado. O processo levou para um esquema dimensional idêntico ao detectado em Portugal.

Em seguida, realizou-se uma regressão, que teve o objetivo de conhecer o poder explicativo dessas dimensões em relação às intenções de abandono da organização (Alpha: 0,80). A variância explicada ficou em $26 \%$, cabendo grande poder explicativo ao espírito de camaradagem e ao comportamento respeitador da parte dos superiores.

A segunda etapa iniciou-se com o aprimoramento do instrumento. As duas últimas dimensões autentizóticas repousavam em apenas dois itens, situa- ção indesejável para as análises fatoriais confirmatórias (Byrne, 1998). Por outro lado, a última dimensão revelou consistências internas inferiores a 0,70 (Nunnally, 1978). Para responder a estas limitações, acrescentaram-se quatro itens referentes à dimensão "conciliação trabalho-família", e três relacionadas ao "sentido de autodeterminação". Elaborou-se então um novo questionário, e colheram-se dados em Portugal e no Brasil. A amostra portuguesa compreendeu 161 membros de 123 organizações. Desses, 11\% trabalhavam em empresas públicas, $24 \%$ eram do sexo feminino, e sua média de idade era de 27,0 anos. A amostra brasileira compreendeu 160 membros de 70 organizações. Desses, $21 \%$ trabalhavam em empresas públicas, $44 \%$ eram do sexo feminino, e sua média de idade era de 32,8 anos.

Além de terem sido convidados a assinalar a natureza autentizótica de suas organizações, solicitou-se aos participantes que respondessem a um questionário de medida do comprometimento, previamente desenvolvido e validado em contexto luso-brasileiro (Rego e Souto, 2002). Os indivíduos foram convidados a assinalar em que grau cada uma das 14 afirmações era aplicável a si próprios, mediante uma escala do tipo Likert de sete pontos (1: "não se aplica rigorosamente a mim" ... 7: "aplica-se completamente a mim").

Os dados relativos a cada construto foram submetidos a análises fatoriais confirmatórias, com o recurso ao método da máxima verossimilhança (Byrne, 1998). Para as características autentizóticas, testou-se o modelo de seis componentes identificado no estudo de Rego (2003) e na replicação realizada no Brasil. Os índices de ajustamento revelaram-se insatisfatórios, tendo sido removidos alguns itens, de acordo com os índices de modificação e os resíduos estandardizados (Byrne, 1998). O modelo reduziu-se a 21 itens, dele emergindo cinco fatores, pois foram suprimidos todos os descritores relativos ao fator "sentido de autodeterminação". O ajustamento do modelo revelou-se bastante satisfatório (veja Tabela 1).

Atendendo ao conteúdo semântico dos itens relativos à dimensão "comportamento respeitador da parte do superior", procedeu-se a sua bipartição: credibilidade e comunicação aberta com o superior. Testou-se então o modelo de seis fatores resultante dessa partição, tendo-se assistido a um incremento nos índices de ajustamento (veja Tabela 1). Finalmente, testou-se o modelo unidimensional, no qual os 21 descritores foram imputados a um só fator. Os resulta- 
dos sugeriram o seu nível insatisfatório de ajustamento (GFI: 0,77 ), pelo que não há razões psicométricas para reunir os diversos itens em uma só dimensão.

Para o comprometimento, testou-se o modelo tridimensional (Rego e Souto, 2002). De acordo com os índices de modificação e os resíduos estandardizados, e tendo como objetivo elevar os índices de ajustamento do modelo, removeram-se três itens, ficando o modelo final reduzido a 11 itens (veja Tabela 2). Os índices de ajustamento são satisfatórios, os lambdas

Tabela 1 - Características autentizóticas: análises fatoriais confirmatórias*.

\begin{tabular}{|c|c|c|}
\hline CARACTERÍSTICAS & 5 FATORES & 6 FATORES \\
\hline Espírito de camaradagem & $(0,82)$ & $(0,82)$ \\
\hline Existe um sentido de família entre os colaboradores. & 0,61 & 0,61 \\
\hline As pessoas preocupam-se com o bem-estar dos outros. & 0,76 & 0,76 \\
\hline Há um grande espírito de equipe. & 0,80 & 0,80 \\
\hline A atmosfera da organização é amistosa. & 0,78 & 0,78 \\
\hline Comportamento respeitador da parte do superior & $(0,85)$ & \\
\hline Credibilidade e confiança do superior & & $(0,82)$ \\
\hline As pessoas têm grande confiança nos superiores. & 0,70 & 0,75 \\
\hline Os superiores cumprem as suas promessas. & 0,76 & 0,80 \\
\hline As pessoas sentem que os superiores são honestos. & 0,75 & 0,79 \\
\hline Comunicação aberta e franca com o superior & & $(0,75)$ \\
\hline As pessoas sentem-se livres para comunicar franca e abertamente com os superiores. & 0,74 & 0,79 \\
\hline As pessoas sentem-se à vontade para mostrar que discordam das opiniões dos seus superiores. & 0,66 & 0,71 \\
\hline É fácil falar com as pessoas situadas em níveis hierárquicos superiores. & 0,60 & 0,63 \\
\hline Oportunidades de desenvolvimento e aprendizagem & $(0,72)$ & $(0,72)$ \\
\hline As pessoas sentem que podem aprender continuamente. & 0,64 & 0,64 \\
\hline As pessoas podem colocar a sua criatividade e imaginação ao serviço do trabalho e da organização. & 0,64 & 0,64 \\
\hline As pessoas sentem que Ihes são atribuídas responsabilidades importantes. & 0,63 & 0,63 \\
\hline As pessoas sentem que podem desenvolver as suas potencialidades. & 0,77 & 0,77 \\
\hline Eqüidade & $(0,72)$ & $(0,72)$ \\
\hline $\begin{array}{l}\text { Quando se obtêm bons resultados devido aos esforços dos colaboradores, as recompensas e os } \\
\text { elogios são distribuídos apenas por um número reduzido de chefias.(i) }\end{array}$ & 0,59 & 0,59 \\
\hline As pessoas sentem-se discriminadas.(i) & 0,79 & 0,80 \\
\hline Há favoritismos pessoais nas promoções.(i) & 0,65 & 0,65 \\
\hline Conciliação trabalho-família & $(0,76)$ & $(0,76)$ \\
\hline Esta organização ajuda as pessoas a conciliar o trabalho com a vida familiar. & 0,90 & 0,90 \\
\hline $\begin{array}{l}\text { A organização preocupa-se em que as pessoas conciliem o trabalho com as suas responsabilida- } \\
\text { des familiares. }\end{array}$ & 0,75 & 0,75 \\
\hline Para se progredir na carreira, é necessário sacrificar a vida familiar.(i) & $-0,45$ & $-0,45$ \\
\hline A empresa cria condições para que as pessoas acompanhem a educação dos seus filhos. & 0,58 & 0,58 \\
\hline \multicolumn{3}{|l|}{ Índices de ajustamento } \\
\hline Qui-quadrado/Graus de liberdade & 2,40 & 2,20 \\
\hline Root mean square error of approximation & 0,07 & 0,06 \\
\hline Goodness of fit index & 0,89 & 0,90 \\
\hline Adjusted goodness of fit index & 0,85 & 0,87 \\
\hline Comparative fit index & 0,91 & 0,93 \\
\hline Incremental fit index & 0,91 & 0,93 \\
\hline Relative fit index & 0,84 & 0,85 \\
\hline
\end{tabular}

* Solução completamente estandardizada. Entre parênteses: Alpha de Cronbach. $\quad$ (i) As cotações nestes itens foram invertidas. 
situam-se invariavelmente acima de 0,50, e os alphas, com uma única exceção, situam-se acima de 0,70.

\section{RESULTADOS}

A Tabela 3 reproduz as médias, os desvios padrão e as correlações entre variáveis. Globalmente, as cotações nas dimensões autentizóticas são moderadas, sendo mais modestas aquelas relativas à eqüidade $e$ à conciliação trabalho-família. Esse padrão é comum às duas amostras, embora se verifique que os indivíduos da amostra brasileira apresentem percepções menos positivas do que os seus congêneres portugueses.
O comprometimento afetivo é moderado, sendo mais fracas as orientações nos outros dois componentes. As variáveis autentizóticas estão associadas entre si, sendo mais modestos os coeficientes relativos à conciliação trabalho-família. O comprometimento afetivo tende a associar-se positivamente com o normativo e negativamente com o instrumental. Entre os componentes normativo e instrumental, as relações não são estatisticamente significativas. Todas as dimensões autentizóticas se associam positivamente com o comprometimento afetivo, sendo menos marcante a associação dessas dimensões com o normativo. Cinco das variáveis autentizóticas relacionam-se negativamente com o comprometimento instrumental, mas apenas na amostra portuguesa.

Tabela 2 - Comprometimento: análises fatoriais confirmatórias *.

\section{CARACTERÍSTICAS}

\section{Comprometimento afetivo}

Importo-me realmente com o destino da minha organização.

Tenho orgulho em dizer a outras pessoas que faço parte desta organização.

Sinto-me "parte da família" da minha organização.

Sinto que existe uma forte ligação afetiva entre mim e a minha organização.

\section{Comprometimento normativo}

Mesmo que isso me trouxesse vantagens, sinto que não deveria abandonar a minha organização agora.

Não deixaria a minha organização agora porque sinto obrigações para com as pessoas que aqui trabalham.

Sinto que, se recebesse uma oferta de melhor emprego, não seria correto deixar a minha organização.

\section{Comprometimento instrumental}

Mantenho-me nesta organização porque sinto que não conseguiria facilmente entrar noutra organização.

Continuo nesta organização porque, se saísse, teria que fazer grandes sacrifícios pessoais.

Sinto que tenho poucas alternativas de emprego se deixar esta organização.

Mantenho-me nesta organização porque sinto que tenho poucas oportunidades noutras organizações.

Îndices de ajustamento

Qui-quadrado/Graus de liberdade

Root mean square error of approximation

Goodness of fit index

Adjusted goodness of fit index

Comparative fit index

Incremental fit index

Relative fit index

* Solução completamente estandardizada.

Entre parênteses: Alphas de Cronbach.

\begin{tabular}{|c|c|c|}
\hline $\begin{array}{c}\text { AMOSTRA } \\
\text { PORTUGUESA }\end{array}$ & $\begin{array}{c}\text { AMOSTRA } \\
\text { BRASILEIRA }\end{array}$ & TOTAL \\
\hline $\mathbf{0}, \mathbf{8 2})$ & $\mathbf{( 0 , 8 1 )}$ & $\mathbf{( 0 , 8 1 )}$ \\
\hline 0,65 & 0,74 & 0,71 \\
\hline 0,65 & 0,69 & 0,68 \\
\hline 0,79 & 0,72 & 0,74 \\
\hline 0,85 & 0,73 & 0,76 \\
\hline $\mathbf{0 , 8 3}$ & $\mathbf{0 , 6 7}$ & $\mathbf{0 , 7 5}$ \\
\hline 0,80 & 0,62 & 0,70 \\
\hline 0,88 & 0,68 & 0,78 \\
\hline 0,71 & 0,64 & 0,66 \\
\hline$(0,83)$ & $(0,80)$ & $(0,81)$ \\
\hline 0,69 & 0,65 & 0,66 \\
\hline 0,55 & 0,51 & 0,54 \\
\hline 0,84 & 0,86 & 0,84 \\
\hline 0,87 & 0,85 & 0,86 \\
\hline & & \\
\hline 2,30 & 1,80 & 2,90 \\
\hline 0,09 & 0,07 & 0,08 \\
\hline 0,90 & 0,92 & 0,94 \\
\hline 0,84 & 0,87 & 0,90 \\
\hline 0,93 & 0,94 & 0,94 \\
\hline 0,94 & 0,94 & 0,94 \\
\hline 0,85 & 0,83 & 0,88 \\
\hline & & \\
\hline
\end{tabular}


A Tabela 4 exibe as análises de regressão. O comprometimento afetivo é o que recebe maior poder explicativo das variáveis autentizóticas. Em ambas as amostras, o espírito de camaradagem e as oportunidades de aprendizagem e desenvolvimento explicam o comprometimento afetivo. Na amostra brasileira, esse vínculo também é explicado pela credibilidade do superior. Nas duas amostras, a credibilidade do superior explica o comprometimento normativo, mas as oportunidades de aprendizagem e desenvolvimento apenas explicam esse vínculo na amostra brasileira. Finalmente, a variância explicada do comprometimento instrumental é quase nula na amostra brasileira, mas chega a $20 \%$ na portuguesa. As dimensões autentizóticas com maior capacidade explicativa desse vínculo são a credibilidade do superior e a comunicação aberta e franca com ele. Nesse caso, porém, o poder de predição é negativo.

Um aspecto relevante é o que diz respeito ao poder explicativo negativo prestado pela eqüidade ao comprometimento afetivo dos indivíduos da amostra bra- sileira. O dado surpreende porque as duas variáveis se correlacionam positivamente (veja Tabela 3). Uma análise minuciosa dos dados permite, todavia, verificar que essa dimensão interage com a credibilidade do superior. Quando o produto dessas duas variáveis é adicionado à regressão, a variância explicada sobe a 34\%, e o beta desse produto fica em $0,72(\mathrm{p}<0,01)$. Observe-se que a baixa credibilidade do superior é especialmente nefasta para o comprometimento afetivo quando a eqüidade é elevada. Pode-se perguntar se é o contraste de percepções projetadas sobre as duas vertentes que explica essa reação extremada dos indivíduos.

A Tabela 5 expõe quatro configurações autentizóticas, inclusive os respectivos níveis de comprometimento. O processo resultou de uma análise de clusters com base nas dimensões autentizóticas. Para medir a distância entre os indivíduos, usou-se o quadrado da distância euclidiana. O critério de agregação foi o método Ward. A tendência é a seguinte: as pessoas percebendo as organizações como mais autentizóticas revelam níveis superiores de comprometimento normati-

Tabela 3 - Médias, desvios padrão e correlações.

\begin{tabular}{|c|c|c|c|c|c|c|c|c|c|c|}
\hline CARACTERÍSTICA & MÉDIA & DP & 1 & 2 & 3 & 4 & 5 & 6 & 7 & 8 \\
\hline \multirow{2}{*}{$\begin{array}{l}\text { 1. Espírito de } \\
\text { camaradagem (\#) }\end{array}$} & 4,2 & 0,9 & - & & & & & & & \\
\hline & 3,8 & 1,1 & - & & & & & & & \\
\hline \multirow{2}{*}{$\begin{array}{l}\text { 2. Credibilidade do } \\
\text { superior (\#) }\end{array}$} & 4,2 & 1,0 & $0,61 * * *$ & - & & & & & & \\
\hline & 3,7 & 1,2 & $0,62 * * *$ & - & & & & & & \\
\hline \multirow{2}{*}{$\begin{array}{l}\text { 3. Comunicação } \\
\text { aberta e franca } \\
\text { com o superior (\#) }\end{array}$} & 4,1 & 1,0 & $0,51 * * *$ & $0,61 * * *$ & - & & & & & \\
\hline & 3,8 & 1,3 & $0,58 * * *$ & $0,63 * * *$ & - & & & & & \\
\hline \multirow{2}{*}{$\begin{array}{l}\text { 4. Oportunidades } \\
\text { de aprendizado } \\
\text { e desenvolvimento } \\
\text { pessoal (\#) }\end{array}$} & 4,3 & 0,8 & $0,58 * * *$ & $0,65 * * *$ & $0,65 * * *$ & - & & & & \\
\hline & 4,1 & 1,0 & $0,56 * * *$ & $0,54 * * *$ & $0,59 * * *$ & - & & & & \\
\hline \multirow{2}{*}{ 5. Eqüidade (\#) } & 3,8 & 1,1 & $0,49 * * *$ & $0,54 * * *$ & $0,60 * * *$ & $0,49 * * *$ & - & & & \\
\hline & 3,1 & 1,2 & $0,49 * * *$ & $0,57 * * *$ & $0,55^{* * *}$ & $0,41 * * *$ & - & & & \\
\hline \multirow{2}{*}{$\begin{array}{l}\text { 6. Conciliação } \\
\text { trabalho-família (\#) }\end{array}$} & 3,6 & 1,0 & $0,41 * * *$ & $0,30 * * *$ & $0,30 * * *$ & $0,17^{*}$ & $0,28 * * *$ & - & & \\
\hline & 3,4 & 1,1 & $0,42 * * *$ & $0,26 * * *$ & $0,37 * * *$ & $0,26 * * *$ & $0,29 * * *$ & - & & \\
\hline \multirow{2}{*}{$\begin{array}{l}\text { 7. Comprometimento } \\
\text { afetivo (\#\#) }\end{array}$} & 4,8 & 1,0 & $0,60 * * *$ & $0,46 * * *$ & $0,37 * * *$ & $0,55^{* * *}$ & $0,39 * * *$ & $0,30 * * *$ & - & \\
\hline & 4,8 & 1,4 & $0,48 * * *$ & $0,51 * * *$ & $0,41 * * *$ & $0,43 * * *$ & $0,23^{* *}$ & $0,28 * * *$ & - & \\
\hline \multirow{2}{*}{$\begin{array}{l}\text { 8. Comprometimento } \\
\text { normativo (\#\#) }\end{array}$} & 3,5 & 1,4 & $0,27 * * *$ & $0,33 * * *$ & $0,26 * * *$ & $0,30 * * *$ & $0,15^{*}$ & 0,04 & $0,42 * * *$ & - \\
\hline & 3,6 & 1,4 & $0,29 * * *$ & $0,35 * * *$ & $0,30 * * *$ & $0,36 * * *$ & $0,15^{*}$ & 0,13 & $0,48 * * *$ & - \\
\hline \multirow{2}{*}{$\begin{array}{l}\text { 9. Comprometimento } \\
\text { instrumental (\#\#) }\end{array}$} & 2,4 & 1,0 & $-0,17^{*}$ & $-0,41 * * *$ & $-0,37 * * *$ & $-0,35 * * *$ & $-0,26 * * *$ & 0,01 & $-0,24^{* *}$ & $-0,12$ \\
\hline & 2,9 & 1,3 & $-0,05$ & $-0,12$ & $-0,04$ & $-0,04$ & $-0,10$ & $-0,10$ & $-0,27 * * *$ & $-0,07$ \\
\hline
\end{tabular}

Notas: Primeira linha: amostra portuguesa; Segunda linha: amostra brasileira.

$* p<0,05 * * p<0,01 * * * p<0,001$

(\#) escala 1-6 (\#\#) escala 1-7

$38 \cdot$ ORAE $\cdot$ VOL. $44 \cdot \mathrm{N}^{0} 3$ 
vo e, sobretudo, afetivo. Inversamente, tendem a mostrar menor orientação instrumental, embora a tendência seja modesta (e quase inexistente na amostra brasileira). Registre-se ainda a elevada quantidade de indivíduos que percebem a organização como psicologicamente "insalubre" e que, concomitantemente, respondem com fracos laços afetivos e normativos.

\section{ANÁLISE E DISCUSSÃo}

Diversas indicações relevantes são possíveis a partir da análise dos dados. A primeira é que os dois instrumentos de medida revelam propriedades psicométricas satisfatórias. A evidência merece destaque por ter sido colhida em contextos culturais distintos. Como

Tabela 4 - Regressões: como as características autentizóticas explicam o comprometimento.

\begin{tabular}{|l|c|c|c|c|c|c|}
\hline \multirow{2}{*}{ CARACTERÍSTICAS } & \multicolumn{3}{|c|}{ AMOSTRA PORTUGUESA } & \multicolumn{3}{c|}{ AMOSTRA BRASILEIRA } \\
\cline { 2 - 7 } & Afetivo & Normativo & Instrumental & Afetivo & Normativo & Instrumental \\
\hline Espírito de camaradagem & $0,38^{* * *}$ & 0,12 & 0,15 & $0,19 *$ & 0,04 & 0,08 \\
\hline Credibilidade do superior & 0,01 & $0,23^{*}$ & $-0,35^{* * *}$ & $0,36^{* * *}$ & $0,24^{*}$ & $-0,18$ \\
\hline Comunicação aberta e franca com o superior & $-0,15$ & 0,09 & $-0,20^{*}$ & 0,04 & 0,05 & 0,10 \\
\hline $\begin{array}{l}\text { Oportunidades de aprendizagem e } \\
\text { desenvolvimento pessoal }\end{array}$ & $0,36 * * *$ & 0,09 & $-0,09$ & $0,16 *$ & $0,23 *$ & 0,00 \\
\hline Eqüidade & 0,08 & $-0,11$ & $-0,02$ & $-0,19 *$ & $-0,13$ & $-0,06$ \\
\hline Conciliação trabalho-família & 0,10 & $-0,10$ & 0,13 & 0,11 & 0,01 & $-0,11$ \\
\hline F & $19,80^{* * *}$ & & $7,48^{* * *}$ & $13,63^{* * *}$ & $5,35^{* * *}$ & 0,85 \\
\hline $\mathrm{R}^{2}$ ajustado & $41 \%$ & $11 \%$ & $20 \%$ & $32 \%$ & $14 \%$ & $0,1 \%$ \\
\hline
\end{tabular}

Notas: $* p<0,05 \quad * * * p<0,001$

Tabela 5 - Configurações organizacionais autentizóticas e níveis de comprometimento.
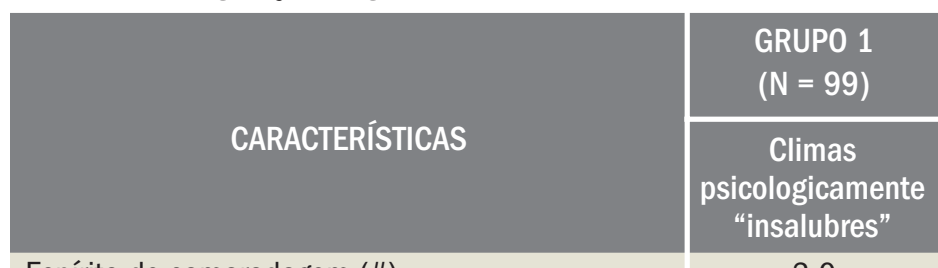

Espírito de camaradagem (\#)

Credibilidade do superior (\#)

Comunicação aberta e franca com o superior (\#)

Oportunidades de aprendizagem e desenvolvimento pessoal (\#)

Eqüidade (\#)

Conciliação trabalho-família (\#)

Amostra portuguesa

C. afetivo (\#\#)

C. normativo (\#\#)

C. instrumental (\#\#)

Amostra brasileira

C. afetivo (\#\#)

C. normativo (\#\#)

C. instrumental (\#\#)

\begin{tabular}{|c|}
\hline GRUP0 2 \\
$(\mathrm{~N}=65)$
\end{tabular}

3,0

2,7

2,9

3,3

2,5

3,0

4,0

2,8

2,9

4,0

3,1

3,0

4,0

3,8

3,5

4,0

3,5

3,3

4,7

3,4

2,7

4,8

3,5

3,3

\begin{tabular}{|c|}
\hline GRUP0 3 \\
$(\mathrm{~N}=132)$ \\
\hline $\begin{array}{c}\text { Climas } \\
\text { moderadamente } \\
\text { autentizóticos }\end{array}$ \\
\hline
\end{tabular}

GRUPO 4

$(\mathrm{N}=25)$

Climas

verdadeiramente autentizóticos
4,4

4,6

4,6

4,7

3,8

3,7

4,9

3,7

2,2

5,4

4,1

2,8
5,4

5,6

5,6

5,5

5,6

4,7

6,1

4,2

1,5

6,3

4,7

2,2

Notas: (\#) escala 1-6; (\#\#) escala 1-7. 
nota particular, registra-se que, embora o modelo de seis dimensões autentizóticas revele apenas pequenos incrementos de ajustamento relativamente ao modelo de cinco dimensões, os dados relativos à explicação do comprometimento sugerem que a partição do fator "comportamento respeitador da parte do superior" em duas dimensões é recomendável. Na verdade, na maior parte dos casos, apenas uma delas emerge com potencial explicativo significativo (veja Tabela 4). Disso não decorre a irrelevância da outra, mas apenas que cada uma pode exercer efeitos distintos sobre diferentes variáveis.

A segunda indicação é que algumas características autentizóticas explicam o comprometimento normativo e, sobretudo, o afetivo. As que facultam maior poder explicativo são o "espírito de camaradagem" e a "credibilidade do superior". Esses dados são convergentes com os que têm sido obtidos, por exemplo, a propósito da liderança transformacional, do apoio do superior, do apoio organizacional e do apoio dos pares (Allen e Meyer, 1996, 2000). Com isso, reforçam a importância dos comportamentos de liderança, assim como do clima social organizacional, e apontam para a necessidade de os líderes zelarem pela credibilidade e confiança que os colaboradores projetam sobre eles. Ainda sugerem que as pessoas, quando se sentem apoiadas e tratadas com dignidade e respeito, desenvolvem laços afetivos e normativos com a organização, seja porque se identificam com ela, porque sentem que a relação com ela é valiosa, ou porque sentem o dever de atuar reciprocamente.

A outra variável autentizótica denotando poder de predição dos comprometimentos afetivo (ambas as amostras) e normativo (amostra brasileira) é a referente às oportunidades de aprendizagem e desenvolvimento. Essa evidência parece convergir com os dados relativos às tarefas desafiantes (Allen e Meyer, 1990), mas ultrapassa o seu âmbito. Coloca em lugar de destaque a necessidade de as organizações darem aos colaboradores a oportunidade de aprenderem continuamente, de colocarem a criatividade e a imaginação ao serviço do trabalho e da organização, e de desenvolverem as suas potencialidades.

O terceiro aspecto digno de nota diz respeito ao comprometimento instrumental. Seria razoável supor que as oportunidades de desenvolvimento e aprendizagem aumentassem o potencial de empregabilidade dos indivíduos, conferindo-lhes mais alternativas de emprego. Conseqüentemente, era de se esperar que essa dimensão autentizótica explicasse tal faceta do comprometimento. Porém, embora a correlação positiva tenha sido detectada (veja tabela 3), a análise de regressão não sugeriu poder explicativo significativo.

Sobre o comprometimento instrumental, cabe ainda observar que é explicado por duas características autentizóticas relacionadas com o comportamento do superior na amostra portuguesa. O dado pode surpreender pelo fato de que esse laço psicológico tende a ser explicado por aspectos relacionados com a percepção de ausência de alternativas ou com "investimentos" dos indivíduos na organização, cujos retornos seriam perdidos com a saída. Aparentemente, a credibilidade ou confiança do superior e a comunicação aberta com ele não representam tais aspectos "instrumentais". Todavia, uma hipótese explicativa plausível existe: os indivíduos percebem que uma eventual saída da organização pode interromper a recepção desses "benefícios sociais e relacionais" oriundos do superior, ou seja, a interpretação dos prejuízos causados por um eventual abandono da organização pode gerar impacto no domínio social e relacional.

O fato de essa tendência ter sido detectada apenas na amostra portuguesa sugere a necessidade de os estudos serem culturalmente contextualizados. Esta representa a quarta indicação apresentada pelos dados. Na verdade, algumas divergências entre as duas amostras foram identificadas, fato que reforça a noção segundo a qual os antecedentes do comprometimento são culturalmente contingentes. Nesse caso, é igualmente possível a interferência do contexto econômico. Poderá acontecer que os colaboradores brasileiros percebam que as condições econômicas são menos propícias à mudança de organização do que em Portugal. Poderão sentir que a permanência na empresa representa um "capital" que não podem facilmente substituir transferindo-se para outras organizações. Poderão ainda perceber que, mesmo que as condições auntentizóticas na atual organização sejam menos positivas, isso não é razão suficiente para desejarem mudar. Note-se que essas suposições têm suporte no fato de que o nível médio de comprometimento na amostra brasileira foi superior ao detectado na portuguesa. Alternativamente a essas explicações, cabe considerar a possibilidade de as duas amostras terem naturezas distintas.

O quinto elemento que merece citação diz respeito ao fato de algumas variáveis autentizóticas não explicarem o comprometimento. Daqui não se deve deduzir que são dispensáveis; por um lado, porque é possível que as variáveis interajam - reforçando-se mutua- 
mente, ou cada uma mitigando o efeito das outras; e por outro lado, porque pode haver variáveis mediadoras e moderadoras afetando a relação. Por exemplo, pode ocorrer que algumas características autentizóticas expliquem o comprometimento dos indivíduos de um dado sexo, de um certo nível de escolaridade, mas não de outros. Aliás, um pequeno exercício realizado a posteriori neste trabalho permite verificar que as oportunidades de aprendizagem e desenvolvimento explicam o comprometimento afetivo dos indivíduos mais jovens e mais recentes na organização - mas tal não ocorre entre os mais velhos e os mais antigos.

O sexto aspecto relevante é a "surpresa" gerada pelo fato de a eqüidade surgir sem apresentar poder explicativo do comprometimento. Embora o dado possa parecer conflitante com a literatura, talvez não o seja. Na realidade, e de acordo com o modelo dos efeitos diferenciais (Sweeney e McFarlin, 1993), as dimensões de justiça predominantes na explicação do comprometimento são a procedimental e a interacional, não a distributiva (Allen e Meyer, 1996; Rego e Souto, 2002). Uma leitura atenta dos itens de medida da eqüidade permite verificar que a dimensão não distingue os aspectos distributivos dos procedimentais e que não contempla nenhuma tendência interacional.

\section{CONCLUSÃO}

Algumas notas são agora dedicadas às limitações da pesquisa e possíveis caminhos de investigação futura.

A primeira limitação relaciona-se ao fato de os dados das variáveis dependentes e independentes terem sido colhidos na mesma fonte e simultaneamente. Daqui derivam riscos de variância do método comum (Podsakoff e Organ, 1986), que futuros estudos deverão evitar. Um caminho possível é a coleta de dados em indivíduos distintos, como, por exemplo, enquanto alguns descrevem as características organizacionais, outros reportam as suas atitudes. Uma outra possibilidade é a coleta de dados em diferentes momentos.

A segunda limitação diz respeito a algumas dimensões autentizóticas mencionadas por Kets de Vries, que não emergem no construto. Esse é um resultado psicométrico originado, talvez, do fato de se terem colhido itens em literatura diversa, e não apenas na estritamente relativa às organizações autentizóticas. Do ponto de vista da riqueza empírica do construto, essa opção parece ter bom resultado, já que se obtiveram dimensões potencialmente pertinentes que Kets de Vries não explicitou com nitidez. Entretanto, pode ser vantajoso que futuras investigações incluam outras variáveis autentizóticas.

A terceira limitação refere-se à ausência de variáveis mediadoras e moderadoras, que poderão também ser incorporadas em futuros estudos.

A quarta limitação relaciona-se ao seguinte ponto: é relevante saber em que grau as variáveis autentizóticas aqui contempladas explicam outras variáveis dependentes, em especial os comportamentos de cidadania organizacional, o absenteísmo, o turnover, a satisfação no trabalho, os comportamentos de retaliação, os contratos psicológicos, o estresse e a saúde, o bem-estar afetivo no trabalho, as atitudes perante a mudança e o desempenho individual. É igualmente recomendável que se teste o poder de predição das características autentizóticas para o desempenho das equipes e organizações.

Cabe observar que, apesar das limitações assinaladas, o presente estudo lança alicerces para que novas pesquisas testem a premissa implícita no trabalho de Kets de Vries: a de que as organizações autentizóticas permitem conciliar a "saúde" organizacional com a saúde física e psicológica dos indivíduos.

\section{REFERÊNCIAS BIBLIOGRÁFICAS}

ALLEN, N. J.; MEYER, J. P. The measurement and antecedents of affective, continuance, and normative commitments to the organization. Journal of Occupational Psychology, v. 63, n. 1, p. 1-8, 1990.

ALLEN, N. J.; MEYER, J. P. Affective, continuance, and normative commitment to the organization: an examination of construct validity. Journal of Vocational Behavior, n. 49, p. 252-276, 1996.

ALLEN, N. J.; MEYER, J. P. Construct validation in organizational behavior research: The case of organizational commitment. In: GOFFIN, R. D.; HELMES, E. (Eds.) Problems and Solutions in Human Assessment: Honoring Douglas N. Jackson at Seventy. Norwell, MA: Kluwer Academic, 2000. p. 285-314.

BECKER, T. E. Foci and bases of commitment: are they distinctions worth making? Academy of Management Journal, v. 35, n. 1, p. 232-244, 1992.

BOLON, D. S. Organizational citizenship behavior among hospital employees: a multidimensional analysis involving job satisfaction and organizational commitment. Hospital e Health Services Administration, v. 42, n. 1, p. 221-241, 1997. 
BOWLES, M. The myth of management: direction and failure in contemporary organizations. Human Relations, v. 50, n. 7, p. 779-803, 1997.

BURKE, M. J.; BORUCKI, C. C.; KAUFMAN, J. D. Contemporary perspectives on the study of psychological climate: a commentary. European Journal of Work and Organizational Psychology, v. 3, n. 1, p. 325-340, 2002.

BURROUGHS, S. M.; EBY, L. T. Psychological sense of community at work: a measurement system and explanatory framework. Journal of Community Psychology, v. 26, n. 6, p. 509-532, 1998.

BYRNE, B. M. Structural equation modeling with lisrel, prelis, and simplis. London: Lawrence Erlbaum, 1998.

COOPER, C. L.; DEWE, P.; O'DRISCOLL, M. Organizational stress. A review and critique of theory, research and applications. London: Sage, 2001.

DE GEUS, A. The living company. Harvard Business Review, v. 75, n. 2, p. 51-59, 1997a.

DE GEUS, A. The living company: habits for survival in a turbulent business environment. Boston: Harvard Business School, 1997b.

DEN DULK, L.; VAN DOORNE-HUISKES, A.; SCHIPPERS, J. Organizações "amigas da família": uma comparação internacional. Sociologia - Problemas e Práticas, n. 29, p. 31-50, 1999.

EUROPEAN COMMISSION. Guidance on work-related stress. Luxembourg: European Communities, 1999.

FINEGAN, J. E. The impact of person and organizational values on organizational commitment. Journal of Occupational and Organizational Psychology, v. 73, n. 2, p. 149-169, 2000.

GANSTER, D. C.; MURPHY, L. Workplace interventions to prevent stressrelated illness: Lessons from research and practice. In: COOPER, C. L.; LOCKE, E. A. (Eds.). Industrial and organizational psychology: linking theory with practice. Malden, MA: Blackwell, 2000. p. 34-50.

GLICK, W. Conceptualizing and measuring organizational and psychological climate: Pitfalls in multilevel research. Academy of Management Review, v. 10, n. 3, p. 601-616, 1985.

GRUNBERG, L.; ANDERSON-CONNOLLY, R.; GREENBERG, E. S. Surviving layoffs: the effects on organizational commitment and job performance. Work and Occupations, v. 27, n. 1, p. 7-31, 2000.

HART, P. M.; COOPER, C. L. Occupational stress: toward a more integrated framework. In: ANDERSON, N.; ONES, D. S.; SINANGIL, H. K.; VISWESVARAN, C. (Eds.) Handbook of industrial, work and organizational psychology. London: Sage, 2001. p. 93-114.

IVERSON, R. D.; BUTTIGIEG, D. M. Affective, normative and continuance commitment: can the 'right kind' of commitment be managed? Journal of Management Studies, v. 36, n. 3, p. 307-333, 1999.

JONES, A. P.; JAMES, L. R. Psychological climate: dimensions and relationships of individual and aggregated work environment perceptions. Organizational Behavior and Human Performance, v. 23, n. 2, p. 201-250, 1979.
KANUNGO, R. N.; MENDONCA, M. Ethical dimensions of leadership. Thousand Oaks, CA: Sage, 1996.

KETS DE VRIES, M. F. R. Creating authentizotic organizations: wellfunctioning individuals in vibrant companies. Human Relations, v. 1, n. 54, p. 101-111, 2001.

LEVERING, R.; MOSKOWITZ, M. The 100 Best Companies to Work for in America. New York: Doubleday, 1983

LEVERING, R.; MOSKOWITZ, M. The 100 best companies to work for in America. Fortune, v. 137 n. 1, p. 26-35, 1998.

LEVERING, R.; MOSKOWITZ, M. 100 best companies to work for. Fortune, v. 147 , n. 1, p. 41-43, 2003

MACKENZIE, S. B.; PODSAKOFF, P. M.; AHEARNE, M. Some possible antecedents and consequences of in-role and extra-role salesperson performance. Journal of Marketing, v. 62, n. 3, p. 87-98, 1998.

MAIGNAN, I., FERRELL, O. C.; HULT, G. T. M. Corporate citizenship: cultural antecedents and business profits. Journal of the Academy of Marketing Science, v. 4, n. 27, p. 455-469, 1999

MCFARLIN, D. B. \& SWEENEY, P. D. Distributive and procedural justice as predictors of satisfaction with personal and organizational outcomes. Academy of Management Journal, v. 3, n. 35, p. 626-637, 1992.

MEDEIROS, C. A.; ENDERS, W. T. Padrões de comprometimento organizacional e suas características pessoais: como são os comprometidos e os descomprometidos com as organizações. In: ENCONTRO ANUAL DA ASSOCIAÇÃO DOS PROGRAMAS DE PÓS-GRAADUAÇÃO EM ADMINISTRAÇÃO, 1998, Foz do Iguaçu, Anais... Foz do Iguaçu: Anpad, 1998. CD-ROM

MEYER, J. P. Organizational commitment. In: COOPER, C. L.; ROBERTSON, I. T. International Review of Industrial and Organizational Psychology, n. 12, p. 175-228, 1997.

MEYER, J. P.; ALLEN, N. J. A three-component conceptualization of organization commitment. Human Resource Management Review, v. 1, n. 1, p. 61-98, 1991 .

MEYER, J. P.; ALLEN, N. J.; SMITH, C. A. Commitment to organizations and occupations: extension and test of a three-component conceptualization. Journal of Applied Psychology, v. 4, n. 7, p. 538-551, 1993.

MEYER, J. P.; HERSCOVITCH, L. Commitment in the workplace: toward a general model. Human Resource Management Review, v. 11, n. 3, p. 299326,2001

MOORMAN, R. H.; NIEHOFF, B. P.; ORGAN, D. W. Treating employees fairly and organizational citizenship behavior: sorting the effects of job satisfaction, organizational commitment, and procedural justice. Employee Responsibilities and Rights Journal, v. 3, n. 6, p. 209-225, 1993.

NUNNALLY, J. C. Psychometric theory. 2.ed. New York: McGraw-Hill, 1978

PAVULS, U. Exploratory factor analysis of organizational commitment in Eastern Europe. 2000. Trabalho apresentado ao XXVII International Congress of Psychology, Stockholm, Sweden, 2000. Não publicado. 
PODSAKOFF, P. M.; MACKENZIE, S. B.; BOMMER, W. H. Transformational leader behaviors and substitutes for leadership as determinants of employee satisfaction, commitment, trust, and organizational citizenship behaviors. Journal of Management, v. 2, n. 22, p. 259-298, 1996.

PODSAKOFF, P. M.; ORGAN, D. W. Self-reports in organizational research: problems and prospects. Journal of Management, v. 12, n. 4, p. 531- 544, 1986.

RANDALL, M. L.; CROPANZANO, R.; BORMANN, C. A.; BIRJULIN, A. Organizational politics and organizational support as predictors of work attitudes, job performance, and organizational citizenship behavior. Journal of Organizational Behavior, n. 20, p. 159-174, 1999

REGO, A.; SOUTO, S. Comprometimento organizacional: um estudo lusobrasileiro sobre a importância da justiça. In: ENCONTRO ANUAL DA ASSOCIAÇÃO DOS PROGRAMAS DE PÓS-GRAADUAČ̃̃O EM ADMINISTRAÇÃO, 2002, Salvador, Anais... Salvador: Anpad, 2002. p. 22-25. CD-ROM.

REGO, A. Comportamentos de cidadania organizacional: factor de competitividade e/ou engenharia social? In: Competitividade através das pessoas. Lisboa: RH Editora, p.7-23, 2002a.

REGO, A. Comportamentos de cidadania organizacional. Lisboa: McGrawHill, 2002b.

REGO, A. Organizações autentizóticas: desenvolvimento e validação de um instrumento de medida. Relatório de pesquisa - Universidade de Aveiro, Portugal, 2003. Não publicado.

ROBINSON, S. L. Trust and breach of the psychological contract. Administrative Science Quarterly, v. 41, n. 4, p. 574-599, 1996.
ROCHA, A. S. C.; BASTOS, A. V. Comprometimento do empregado e contextos organizacionais em mudança: o caso do Banco do Brasil. Revista de Ciências Humanas (CFH/UFSC), n. 5, p. 117-140, 2000.

SCOTT, W. R. Organizations: Rational, natural, and open systems. 3. ed. Englewood Cliffs, NJ: Prentice Hall, 1992.

SHORE, L. M.; WAYNE, S. J. Commitment and employee behavior: comparison of affective and continuance commitment with perceived organizational support. Journal of Applied Psychology, v. 78, n. 5, p. 774780, 1993.

SWEENEY, P. D.; McFARLIN, D. B. Workers' evaluations of the 'ends' and the 'means': an examination of four models of distributive and procedural justice. Organizational Behavior and Human Decision Processes, v. 55, n. 1, p. 23-40, 1993.

THOMPSON, C.; BEAUVAIS, L.; LYNESS, K. When work-family benefits are not enough: the influence of work-family culture on benefit utilization, organizational attachment, and work-family conflict. Journal of Vocational Behavior, n. 54, p. 392-415, 1999.

VERGARA, S. C.; BRANCO, P. D. Empresa humanizada: a organização necessária e possível. Revista de Administração de Empresas, v. 41, n. 2, p. 21-30, 2001

\section{NOTA}

Uma versão preliminar deste texto foi apresentada ao XXVII ENCONTRO ANUAL DA ASSOCIAÇÃO NACIONAL DOS PROGRAMAS DE PÓS-GRADUAÇÃO EM ADMINISTRAÇÃO, Atibaia, 2003.

Artigo recebido em 04.11.2003. Aprovado em 25.05.2004.

\section{Arménio Rego}

Professor na Universidade de Aveiro (Portugal). Doutor e Mestre em Gestão de Empresas pelo Instituto Superior de Ciências do Trabalho e da Empresa. Interesses de pesquisa em justiça organizacional, comprometimento, comportamentos de cidadania, liderança, comunicação, climas éticos, organizações autentizóticas e estresse.

E-mail: arego@egi.ua.pt

Endereço: Universidade de Aveiro, Campus de Santiago, Aveiro - Portugal, 3810-193.

\section{Solange Souto}

Professora nas áreas de Comportamento Organizacional e Administração de Recursos Humanos do Ibmec-RJ. M.Sc. em Psicologia pela FGV-RJ. Interesses de pesquisa em comportamento e justiça organizacional, organizações autentizóticas, comportamentos de cidadania e comprometimento, comunicação, liderança e mudança nas organizações. E-mail: s.souto@globo.com Endereço: UERJ, Rua São Francisco Xavier, 524, $2^{\circ}$ andar, bl. F, Maracanã, Rio de Janeiro - RJ, 20550-012. 